\title{
ENSINANDO HISTÓRIA, CULTURA E CIÊNCIAS NO MUSEU - ATIVIDADES INTERDISCIPLINARES PARA FORMAÇÃO DE CRITICIDADE
}

\section{TEACHING HISTORY, CULTURE AND SCIENCE AT THE MUSEUM - INTERDISCIPLINARY ACTIVITIES FOR TRAINING OF CRITICALITY}

\author{
Adriane Gonçalves Gomes ${ }^{1}$,Carlos Roberto Pires Campos $^{2}$, Leonardo Salvalaio Muline ${ }^{3}$ \\ ${ }^{1}$ Instituto Federal de Educação do Espírito Santo/EDUCIMAT/Vitória \\ ${ }^{2}$ Instituto Federal de Educação do Espírito Santo/EDUCIMAT/Campus Vitória, carlosr@ifes.edu.br \\ ${ }^{3}$ Instituto Federal de Educação do Espírito Santo/EDUCIMAT/ Vitória, leonardosalvalaio@ gmail.com
}

\section{RESUMO}

Os espaços educativos não formais, aqui, no caso, o museu, têm se configurado como valiosos colaboradores aos processos de construção do conhecimento científico, adicionando ludicidade à ação pedagógica. Ao proporcionar a ocorrência de ações interdisciplinares de ensino, o espaço museal, sua estrutura, suas exposições, tudo favorece a comunicação efetiva com a escola. A linha tênue que aproxima cultura científica à cultura erudita se materializa no museu, o qual transforma tais conhecimentos, deixando-os mais inteligíveis ao público. O museu socializa o discurso científico, e torna seus conhecimentos acessíveis ao público escolar. Este trabalho apresenta estratégias formativas para professores com vias a alcançar tal proposta de utilização do espaço museal. Enfocamos variadas concepções museológicas e educativas no intuito de apresentar o museu histórico como espaço não formal de ensino e seu papel promissor no processo de construção do conhecimento científico, enfatizando o papel de mediador do professor na abordagem transdisciplinar desse mesmo conhecimento, trazendo, assim professores e alunos para o centro do palco.

Palavras-chave: Educação em espaços educativos não formais, conhecimento científico, transdisciplinaridade, formação continuada, divulgação científica.

\begin{abstract}
The non-formal educational spaces here in case the museum, are characterized as valuable contributors to the processes of construction of scientific knowledge, adding playfulness to the pedagogical action. By providing the occurrence of actions interdisciplinary teaching, the museum space, its structure, its exhibitions, everything favors effective communication with the school. The fine line that approaches scientific culture to high culture is embodied in the museum, which transforms this knowledge, making them more intelligible to the public. The museum socializes scientific discourse, and makes their knowledge accessible to the public school. This paper presents strategies for training teachers with ways to achieve such proposed use of the museum space. We focus on different concepts and educational museum in order to present the historical museum space as non-formal education and its promising role in the construction of scientific knowledge, emphasizing the mediating role of the teacher in transdisciplinary approach that knowledge, thereby bringing teachers and students to the center stage.
\end{abstract}




\section{Ensino, Saúde e Ambiente - V 7 (1), Edição Especial, maio de 2014}

Key words: Non-formal education settings, scientific knowledge, transdiciplinarity, continuing education, science communication.

\section{INTRODUÇÃO}

Até que ponto um convite para ir ao museu pode despertar interesse? Em que medida podemos fazer do museu um espaço dialógico propício para o aprendizado de ciências e de tantos outros temas?

A configuração dos museus históricos e de ciências do modo como são conhecidos hoje decorre de um processo longo de fortes mudanças sociais e culturais, e até políticas. Hoje os museus não se resumem à exposição de coleções de objetos, mas passaram a se configurar como instituições públicas de importante função social, cultural, histórica e educativa.

O museu atual passa por transformações que vêm sendo organizadas pela ICOM (Comitê Internacional de Museologia) com vistas a compor uma nova visão de museu, buscando torná-lo capaz de inserir-se na comunidade de forma atuante, no sentido de despertar a criticidade do público e transformar-se em espaço de dialogicidade e de interação de sujeitos (FREIRE, 1996).

Partimos do pressuposto de que o museu é visível para as pessoas levando-lhes a visibilidade, também, da cultura. A noção de educação museal com a qual trabalhamos intenta desmitificar o papel do museu como "um local conservador elitista ou como um bastião da tradição da alta cultura", defendemos o museu como espaço de "cultura de massa, como um lugar de um mise-en-scène espetacular e de exuberância operística" (HUYSSEN,1997). Desse ponto de vista, defendemos um museu favorecedor, mediador da construção do conhecimento. Isso, porque os museus na atualidade devem ser os "mandachuvas da indústria cultural" (HUYSSEN, 1997). Este novo museu passa ser acompanhado pela importante mudança do perfil dos frequentadores que parecem estar em busca de experiências valiosas, iluminações instantâneas, eventos e espetáculos de grande sucesso, e por que não, da apropriação do conhecimento cultural, cientifico, histórico e memorialístico.

Fiel a esse quadro, este trabalho tem por objetivo destacar o papel do museu como um espaço educativo não formal, promissor no processo de construção do conhecimento científico, enfatizando seu papel de mediador na abordagem transdiciplinar desse mesmo conhecimento. 
Ensino, Saúde e Ambiente - V 7 (1), Edição Especial, maio de 2014

\section{MUSEU E ESCOLA: CONSTRUÇÃO DO CONHECIMENTO CIENTÍFICO POR MEIO DO ESPAÇO MUSEAL}

O atual contexto histórico, social e econômico fez com que o ensino também se reestruturasse a fim de acompanhar sua dinâmica e proporcionar, aos discentes, meios de entender o mundo que os cerca, avançando para um ensino que valoriza o complexo com a premente necessidade de nos interrogar com relação à postura científica que se torna reflexo da sociedade, fragmentada e desconectada, com o valor subjetivo inerente ao ser humano. Urge uma reflexão acerca da maneira como a própria ciência intensifica, por meio dessa postura, os problemas da fragmentação da sociedade em suas mais variadas esferas. É preciso priorizar aprendizagem de conteúdos que possibilitem aos indivíduos fazerem uma leitura do mundo do ponto de vista da compreensão do que se passa ao seu redor, o que é fundamental na educação não formal (GOHN, 2010). Isso significa que a educação não formal pode promover processos de aprendizagem que se desdobram em autoaprendizagem e aprendizagens coletivas, adquiridas a partir da experiência em ações coletivas.

A educação não formal se configura como um meio pelo qual a educação pode avançar no intuito de formar cidadãos críticos e autônomos, isso, porque esta alia, em seu fazer, política e cultura, em busca de uma educação completa que valoriza o ser humano como ser social e historicamente construído. Neste trabalho, defendemos que o espaço museal pode levar o cidadão à alfabetização científica, na medida em que divulga ao público conhecimentos científicos suficientemente práticos e úteis para que aquele possa ponderar sobre as questões sociais com mais conhecimento de causa. (VOGT, 2011). Partindo desse princípio, a educação deveria ser abrangente no sentido de adicionar, ao seu fazer, o uso dos espaços não formais de ensino, de modo a desenvolver a criticidade e a autonomia dos educandos.

O museu, além de ser um espaço integrador, onde professores e alunos poderão construir, e reconstruir, conhecimentos, se destaca como um local de protagonistas em busca do saber. De acordo com Gohn (2010), a educação não formal capacita os indivíduos a se tornarem cidadãos do mundo, no mundo, sua finalidade é abrir as janelas de conhecimento sobre o mundo que circunda os indivíduos e suas relações sociais.

Ademais, a educação em espaços não formais, aqui vista como adicionante no processo de formação cidadã de discentes, para Gohn (2010), articula a escola com a 


\section{Ensino, Saúde e Ambiente - V 7 (1), Edição Especial, maio de 2014}

comunidade educativa de um território, materializando o sonho de aproximar mais tais espaços. A educação não formal desenvolve laços de pertencimento, e ajuda na construção da identidade coletiva do grupo.

Essa reflexão pode ser corroborada por Vygotsky, que em Pensamentos e Linguagens (1998), atesta que toda relação do indivíduo com o mundo é feita por meio de instrumentos e técnicas e linguagem, portadora da cultura do indivíduo e o desenvolvimento do pensamento vai do social para o individual, sendo a aprendizagem uma ação social, em que os sujeitos formulam seus conhecimentos em face de sua interação com o campo e com o outro, numa relação dialógica constante entre sujeito $\mathrm{x}$ contexto, entre individual x coletivo. O fato é que para Vygotsky, (1998) o social é o princípio básico da aprendizagem, e a participação ativa do sujeito favorece a aprendizagem. E, nesse lance, as instituições culturais, os espaços educativos não formais desempenham papel fundamental no desenvolvimento de ações educativas, por meio da mediação mediador x sujeito x objeto x conteúdo.

Diz o autor russo que a mediação configura-se como uma característica cognitiva, que aponta para a assimilação de atividades e ações sociais, históricas e culturais; aponta para uma relação entre sujeito que aprende o mediador, outros sujeitos sociais, o objeto artístico repleto de significância e o contexto com seus valores, tudo em rumo à construção do pensamento e da aprendizagem.

Ao trabalhar com espaços educativos não formais, é necessário compreender que esses colaboram para a alfabetização cientifica dos alunos, na construção do seu conhecimento científico, vez que esse ambiente permite aos educandos participação mais interativa com o conhecimento, transformando seu olhar do senso comum em um olhar científico (que não ocorre de imediato), uma vez que tais espaços são favorecedores desse trânsito. Sobre esse movimento, é pertinente chamar Morin (2000), para quem um dos grandes desafios da educação, na atualidade, reside na proposta de fazer com que os conteúdos ministrados na escola extrapolem o ambiente escolar e que estes possam ir além da sala de aula. Isso quer dizer que os alunos precisam atribuir sentido, e fazer conexões entre os conteúdos disciplinares e seu cotidiano.

A troca intercultural entre museu e escola existe há muito tempo, é uma ação reconhecida por essas duas instituições, visto que a escola se apropria do espaço museal bem como museu tem se adaptado ao público escolar. O museu há muito é reconhecido como um espaço favorecedor de construção do conhecimento, porém a atenção dada a esse espaço no que se refere à mediação e à forma como as informações chegam ao Edição Especial com os melhores trabalhos apresentados no IV ENECiências: UFF - 13 a 16 de maio de 2014. 


\section{Ensino, Saúde e Ambiente - V 7 (1), Edição Especial, maio de 2014}

público, ainda hoje, não é realizada na maioria dos muitos museus, sejam esses de grande, médio ou pequeno porte, fato que vem atravancando o processo de construção do conhecimento científico no espaço museal.

"A preocupação com estas questões têm vindo a ser acompanhada por um esforço visível de renovação das exposições, tornando-as mais apelativas, informativas e acessíveis e, ao mesmo tempo, assiste-se à implementação e desenvolvimento de Serviços Educativos nos grandes museus, agregando técnicos com formação pedagógica. A função destes serviços é sobretudo a de descodificar as mensagens contidas nos discursos expositivos e promover acções de animação que permitam ao visitante atingir facilmente os objectivos "educacionais" da exposição."(BRANDÃO,1996, p . 58)

Santos (2002), ao tratar sobre a importância da interação entre as diversas áreas do conhecimento e o seu necessário reconhecimento histórico social, nos atenta para o fato de que é possível construir conhecimento na troca entre o ensino formal e não formal, partindo, em especial, dos conhecimentos prévios dos sujeitos sociais que estão fora da academia e, portanto, possuem outro olhar sobre determinados assuntos e circunstâncias, podendo, indicar caminhos e soluções, muitas vezes, por nós despercebidos, os quais, também, serão enriquecidos a partir das reflexões e do conhecimento por nós produzido.

[...] compreendemos que a escola é uma instituição que faz parte do patrimônio cultural e, ao mesmo tempo, é alimentada por diversos patrimônios culturais, representados pelo conhecimento produzido e acumulado ao longo dos anos, resultado da herança cultural construída pelos sujeitos sociais ao longo da vida, ou seja, a tradição, que deve ser compreendida, também, como um processo de construção e reconstrução. (SANTOS, 2002, p. 4)

Olhando por esse prisma, Sacristán (2000) nos atenta para a importância da tradição no processo educativo, enfatizando que só se pode pensar a partir do que foi pensado por outros, do que foi conquistado por outros, tal fato nos permite refletir que os esforços, em busca do conhecimento, surgem como um desejo de continuação, que parte da visão de algo que se apresenta relevante, ou seja, de um conhecimento, ou fato, que tenha despertado curiosidade atribuindo, assim, a esse, significado, mais valor. A partir desse ponto, avança-se em busca de continuar a conhecer o que já está feito e conquistado ou parte-se em busca de coisas novas, novos conceitos e experiências.

Considerando o que antes não se considerava, notamos que para tal processo educativo precisamos ter um ponto de partida, sendo viável a seleção de conhecimentos e espaços, trabalhados pelo docente, em suas aulas, sejam essas em espaços formais ou não formais.

Os espaços não formais podem favorecer a busca pelo conhecimento científico, tendo em vista que a facilidade e a forma lúdica como as aulas podem ser conduzidas 


\section{Ensino, Saúde e Ambiente - V 7 (1), Edição Especial, maio de 2014}

nesses espaços ajudam na aprendizagem. No espaço não formal, os discentes podem tocar, visualizar e interagir com o conhecimento.

Assim, este trabalho finca sua relevância em dois pressupostos, o primeiro aponta para a mudança do olhar sobre o espaço museal, não mais como guardião de acervos, e sim como elemento estruturador de políticas culturais. O segundo é que o museu vive, porque enseja ao público uma experiência sensorial, física, memorialística, por isso é aberto e por mais desinteressado, ou interessado, que alguém chegue às suas portas, ao entrar e ao mover-se por seus corredores estará mergulhado no oceano de descobertas, de encontros, de desencontros, de histórias, do começo e do fim, do nadir e do zênite de sua história, da história do mundo, da vida e da morte.

\section{PERCURSO METODOLÓGICO}

\subsection{A PESQUISA}

A presente pesquisa possui natureza qualitativa, etnográfica escolar, seguindo alguns critérios definidos por Lüdke e André (1986) e André (2007). Trata-se de uma pesquisa etnográfica escolar cujos sujeitos envolvidos foram os professores da Rede Pública Municipal de Anchieta. A pesquisa consistiu de três momentos, quais sejam, o primeiro que constou da exposição teórica acerca das aulas em um espaço museal e seu poder interdisciplinar. O segundo momento consistiu da saída a campo com os professores, e, no processo que se seguiu, aplicamos entrevistas semiestruturadas, contendo questões abertas e fechadas, e durante as ações observamos sistematicamente os sujeitos da pesquisa, ou seja, os docentes, para posterior análise. Os dados de campo foram registrados no diário de bordo.

\subsection{LOCAIS DA PESQUISA}

A EMEF Irmã Terezinha Godoy se localiza a aproximadamente 400 metros do Museu Anchieta, sua escolha se deu primordialmente pela sua localização e, consequente, facilidade de locomoção dos professores para a posterior saída a campo ao porto fluvial e ao Museu Anchieta. Estabelecemos nosso foco na escolha do espaço não formal a ser trabalhado, selecionando-o entre outros pela premissa que este porta, em sua estrutura e artefatos, a possibilidade de apresentar os vários conhecimentos sendo possível trabalhá-los em cadeia. Os espaços escolhidos foram o porto e o Museu Anchieta, que, além do espaço museal e acervo, trazem em sua essência a memória e 


\section{Ensino, Saúde e Ambiente - V 7 (1), Edição Especial, maio de 2014}

identidade desta cidade, além de o segundo ser um ícone na história nacional, por sua importância cultural. O Museu Anchieta localiza-se no conjunto arquitetônico da Matriz de N.S. da Assunção, fundado na metade do Século XVI, no platô da feição deltaica do Rio Benevente. Havia, na época de sua fundação, religiosos jesuítas que possuíam escola, produziam ciência e catequizavam os índios. A cidade de Anchieta é a única no sul do estado do Espírito Santo a possuir um museu histórico, ainda que municipal.

\subsection{SUJEITOS e COLETA DE DADOS}

Participaram da pesquisa professores da EMEB "Irmã Terezinha Godoy" sendo esses $40 \%$ do gênero masculino e $60 \%$ do feminino, com idade variando entre 27 a 45 anos, possuindo formação nas diversas áreas, tais como: Ciências, História, Português, Matemática, Química, Física, Geografia. Os dados foram colhidos por meio de observação sistemática e por meio de anotações feitas no diário de bordo. Houve aplicação de entrevistas semiestruturadas, contendo questões abertas e fechadas.

\subsection{O MINI CURSO DE FORMAÇÃO}

Iniciamos justificando o porquê da escolha do Museu Anchieta e do porto fluvial como espaço não formal de nossa pesquisa, demonstrando, ainda, que o intuito era ir além de explorar somente o museu intra-muros, mas trabalhar a cidade, ela própria, seu sitio histórico, seu porto, sua feição deltaica, seu manguezal, suas ruas estreitas, tudo servindo de museu a céu aberto.

Durante a manhã de formação, foi apresentado as profissionais presentes a base teórica da pesquisa composta por Morin (na defesa de um ensino transdiciplinar que é o intuito do presente projeto), bem como Vygotsky, com a teoria da mediação, para resguardar as bases que fundamentam o trabalho. Durante a apresentação, expusemos a teoria que fundamenta os espaços não formais de ensino, conceituando e diferenciando o espaço formal, do não formal e informal, apresentando o museu e as possibilidades de associação do saber nesse ambiente. Os professores participaram de forma ativa, levantando situações e questões pertinentes ao que estava sendo discutido.

Na manhã de formação, uma das nossas preocupações girou em torno de como apresentar o museu como um espaço inteligível, acessível e de diálogo de saberes. Assim, decidimos que o mini-curso deveria seguir pela seguinte vertente: no primeiro momento, justificamos o projeto e a escolha do espaço do museu como foco de pesquisa, defendendo esse como um espaço interdisciplinar visto que abriga diversas Edição Especial com os melhores trabalhos apresentados no IV ENECiências: UFF - 13 a 16 de maio de 2014. 


\section{Ensino, Saúde e Ambiente - V 7 (1), Edição Especial, maio de 2014}

ciências que dialogam entre si, além de apresentar o museu como um espaço favorecedor de ricas interlocuções com a comunidade escolar, capaz de formar cidadãos críticos.

Em seguida, tratamos da parte da fundamentação teórica da pesquisa, enfatizando o que nos diz Morin, sobre transdisciplinaridade e como essa se aplica ao ensino promovido em um espaço não formal como vias à construção do conhecimento científico, defendendo o pensamento do complexo, como aquele que visa a distinguir, sem separar, reunir sem parcelar. O propósito do pensamento complexo é simultaneamente reunir (contextualizar e globalizar), revelar o desafio da incerteza. (MORIN, 2000). Procuramos destacar que o conhecimento não é específico, mas um todo inseparável, portanto ao traçar um caminho para a oferta de uma educação de qualidade, que valorize a formação humana crítica, é preciso ter consciência do ponto de partida, que hoje, é a visão transdisciplinar de ensino. Intentamos com as reflexões em torno da teoria da transdisciplinaridade, enfocar que o pensamento se faz em cadeia e que o intento da presente pesquisa gira em torno de adicionar, na busca por formar cidadãos capazes de articular os diversos saberes entre si.

No momento seguinte, trabalhamos com Vygotsky, no que diz respeito à mediação do conhecimento, tendo enfocado o museu como favorecedor de oportunidades que os professores terão para transformar o senso comum em conhecimento científico, através da mediação em espaços expositivos, defendendo a proposta de que os fenômenos psicológicos são construídos simultaneamente à medida em que os sujeitos interagem socialmente com objetos sensíveis, visíveis, tácteis, olfativos, audíveis.

\subsection{A SAÍDA A CAMPO}

O passo seguinte foi a visita ao museu onde os professores puderam, na prática, perceber como as várias ciências se entrelaçam e formam uma cadeia conexa de conhecimentos. Iniciamos a aula de campo na frente do Museu Anchieta enfocando sua geografia cultural e o porquê da sua escolha para o assentamento jesuítico. Debatemos sobre a estrutura do conjunto arquitetônico, composto por museu, antiga casa dos jesuítas e igreja Nossa Senhora da Assunção, falamos das mudanças ocorridas ao longo do tempo devido à falta de conservação e os usos feitos, no local, que, após a expulsão dos jesuítas, serviu como sede da câmara municipal, e, por um determinado tempo, como cadeia e até como cemitério municipal.

Edição Especial com os melhores trabalhos apresentados no IV ENECiências: UFF - 13 a 16 de maio de 2014. 


\section{Ensino, Saúde e Ambiente - V 7 (1), Edição Especial, maio de 2014}

Ao adentrar no museu Anchieta, atentamos os docentes para sua divisão em 3 salas quais sejam: sala 1 dedicada às artes sacras; sala 2 , onde fica exposta a reserva técnica de arqueologia do museu; e a sala 3 dedicada ao padre Anchieta com a documentação livros e reportagens que tratam sobre sua vida. Dentro do museu, ainda, é possível ver expostos objetos indígenas como lanças, remos, líticos (figuras 1 e 2) que enfatizam na técnica e tecnologia usadas pelos indígenas, e um pouco de história da ciência.

Figura 1 - Lítico

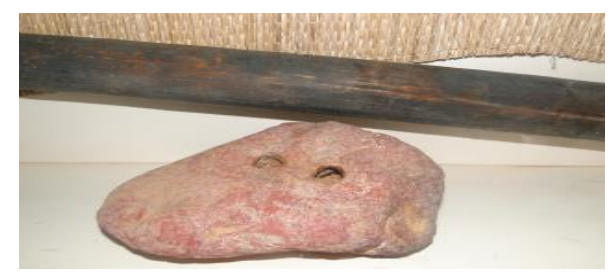

Fonte: os autores, 2013
Figura 2 - Instrumentos indígenas e líticos.

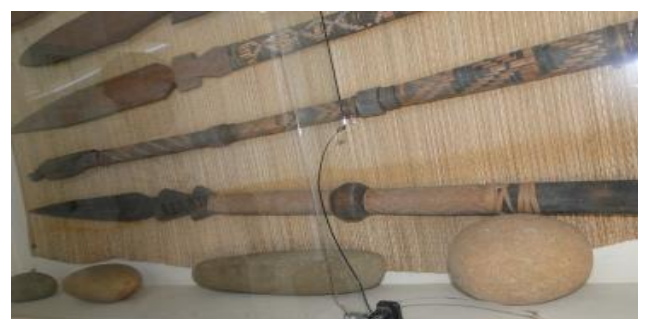

Fonte: os autores, 2013

$\mathrm{Na}$ primeira sala, onde se encontram expostos objetos de arte sacra, foi possível aos professores observarem esculturas em barro e argila correspondentes ao estilo barroco com ênfase nas características do barroco latino, em que as peças se apresentam com características da população indígena. $\mathrm{Na}$ sala 2, que expõe a reserva técnica de arqueologia do museu, contendo a cultura material localizada nas escavações no pátio externo e interno no espaço onde fica a igreja e casa dos jesuítas, do atual museu Anchieta, trabalhamos com os docentes a visão da cultura material e a relação do homem com o objeto, sendo esses objetos interlocutores, e não reflexos de um povo e um local. Entre os registros arqueológicos ali encontrados destacamos as solas de sapato, por meio das quais enfatizamos as relações de poder existentes na sociedade daquela época, visto que sapato era usado somente pela classe dominante.

Foi possível ver ainda frascos de medicação do século XVIII. Cadinhos para realização de medicação e pilões nos remetem ao conhecimento das ervas medicinais, (Figura 3), saberes indígenas compartilhados com os jesuítas, que se dedicavam também à elaboração dessa espécie de alquimia. 


\section{Ensino, Saúde e Ambiente - V 7 (1), Edição Especial, maio de 2014}

Figura 3 - Frascos de medicação do século XVIII

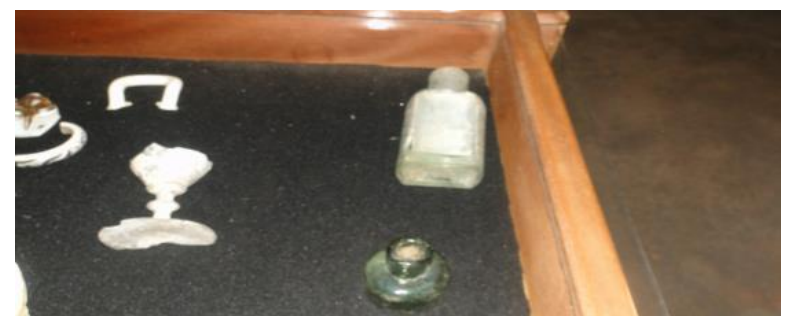

Fonte: Os autores. 2013.

Na sala 3, dedicada à personalidade do Padre Anchieta onde se encontram os registros históricos, localizam-se os documentos escritos que tratam da vida e feitos do Padre Anchieta, além de recortes de jornais e documentos referentes a sua canonização. Nesta sala, ainda, é possível perceber, nas paredes, a técnica de construção empregada, desde conchas usadas para dar liga à massa para a construção, provavelmente retiradas de Sambaquis que ficam ao redor do museu, até pedras e cal, presentes na obra. A própria técnica de construção do partido jesuítico diz sobre a história da ciência, tendo em vista sua localização privilegiada, a partir das constelações e dos conhecimentos de astronomia.

Outro ponto importante que fizemos questão de enfatizar condiz à parte exposta com instrumentos indígenas como lanças e flechas, bem como sua indústria lítica que mostraram aos docentes a oportunidade de trabalhar nesse espaço um pouco de história da ciência por meio da técnica e tecnologia, presentes nesses instrumentos. Quebra coquinhos, pilões, almofarizes, machados, amoladores, tudo em arenito ou rocha à base de óxido de ferro, constituíam-se em ferramentas dóceis no domínio e na domesticação da natureza.

Após a saída a campo, aplicamos entrevistas semiestruturadas aos professores, os quais avaliaram o trabalho e apresentaram suas valiosas contribuições. Passamos a destacar alguns trechos colhidos, os quais merecem notação: Perguntamos se eles conheciam o museu e se já haviam levado seus alunos àquele espaço para uma atividade interdisciplinar:

Professor 1: "Acho viável a proposta porque apesar de sermos professores nessa cidade, nós conhecemos muito pouco da história do município e muito menos ainda do espaço do museu." 
Professor 2: "Já visitei o Museu Anchieta, mas a falta de alguém que entendesse do espaço, dificulta a compreensão do mesmo."

Professor 3: "Penso que a falta de informação e formação dificultam o trabalho em um espaço não formal de ensino."

Reveladoras foram as respostas dos professores, considerando total desconhecimento de atividades simples, mas ricas. A preocupação reside, todavia, no fato de que a ação docente poderia estar centrada nos espaços intra-muros escolares, focando práticas verticais, pouco interdisciplinares e talvez disciplinadoras e não dialógicas.

\section{CONSIDERAÇÕES FINAIS}

Com as práticas realizadas durante a pesquisa, alcançamos os objetivos traçados inicialmente quando nos dispusemos a apresentar aos professores o espaço museal como um ambiente propício à construção do conhecimento científico, sendo que nesse espaço não formal ocorre a valorização do ensino transdisciplinar dos diversos conhecimentos presentes que se apresentam em suas exposições, estrutura e história. Ressaltamos, ainda, que o caminho iniciado com tais práticas é somente um ponto de partida. Profissionais que tiveram a oportunidade de ler o mundo e rever suas práticas, ensejando novas condutas pelo viés transdisciplinar, ganharam um adicionante em sua práxis cotidiana, pois entendemos que a formação continuada é fator primordial para uma práxis educativa significativa.

Pensamos a educação como uma forma de mudança social a partir do momento em que objetiva formar cidadãos críticos e autônomos, defendemos, para tal, a necessidade de profissionais capacitados e atualizados, de modo a proporem uma mudança que se inicia na escola, mas possui sua gênese no professor, por meio do qual alcança os discentes e as estruturas sociais.

\section{REFERENCIAS}

ANDRÉ, Marli D. Etnografia da prática escolar. 9.ed. Campinas: Papirus, 2007. BRANDÃO, José M. Ação cultural e educação em museus. Cadernos de Museologia, n' 5, 19996.

FREIRE, P. Pedagogia da Autonomia. São Paulo: Paz e Terra, 1996.

GOHN, Maria da Glória. Educação não formal e o educador social: atuação no desenvolvimento de projetos. São Paulo: Cortez,2010.

HUYSSEN. Andreas. Memórias do modernismo. Tradução Patrícia Farias. Rio de Janeiro: Ed. UFRJ, 1997.

LÜDKE, Menga e ANDRÉ, Marli E. D. A. Pesquisa em educação: abordagens qualitativas. São Paulo: EPU, 1986.

Edição Especial com os melhores trabalhos apresentados no IV ENECiências: UFF - 13 a 16 de maio de 2014. 
MORIN, Edgar. A inteligência da complexidade. trad. Nurimar Maria Falci . São Paulo, editora Peirópolis, 2000.

SACRISTÁN, José Gimeno. A Educação que temos, a Educação que Queremos, in: A Educação no século XXI: os desafios do futuro imediato/ org. Francisco Imberón; trad. Ernani Rosa. Porto Alegre: Artes Médicas Sul, 2002.

SANTOS, Maria Célia T. Moura. Museu e educação: conceitos e métodos. Ciências \& Letras, Porto Alegre, n.31, p. 307 - 323, jan - jun. 2002.

VYGOTSKY, L.S. Pensamento e linguagem. São Paulo: Martins Fontes, 1998.

VOGT, Carlos. De ciências, divulgação, futebol e bem-estar cultural. PORTO, C.; BROJAS, A.M; BORTOLIERO, S.T.Orgs. Diálogos entre ciência e divulgação científica. Salvador: EDUFBA, 2011. 